\title{
LAS CÉLULAS MADRE
}

\section{STEM CELILS}

Juan Pablo Giraldo, M.D. ", José Ignacio Madero, M.D. *\$, Mabel Ávila, M.D. *\$, Silvio Cuneo, M.D. ${ }^{*}$, Claudia López, M.D. ${ }^{*}$, Magally Escobar, M.D. ${ }^{*}$, Arturo Aparicio, M.D. ", Jesús A. Ruiz, M.D. ${ }^{*}$

Recibido: octubre 2002 - Revisado: diciembre 2002 - Aceptado: febrero 2003

\section{RESUMEN}

La historia de las células madre comenzó ya hace dos décadas durante las cuales se ha producido un cambio radical en el horizonte de la medicina. El reconocimiento de la existencia de varios tipos de linajes celulares provenientes del blastocisto y de la sangre periférica del adulto, junto con su capacidad de producir nuevos tejidos, inclusive de capas embrionarias diferentes, ha permitido diseñar nuevos tratamientos antes considerados imposibles.

Palabras clave: células madre pluripotentes humanas, células madre embrionarias humanas, células madre germinales humanas, ética médica, investigación en embriones humanos, investigación en tejido fetal, transplante de tejido fetal.

\section{ABSTRACT}

The history of the stem cells already accounts two decades, in which these cells have changed men's horizon in the field of medicine. The acknowledgement of the existence of various types of cellular

\footnotetext{
* Medifertil. Programa de Medicina Reproductiva. Calle 127 \# 28-75. Bogotá, Colombia.

$\S$ Profesor Departamento de Obstetricia y Ginecología Universidad Javeriana.
}

lines stemming from the blastocysts and peripheral blood of the adult, along with it's capacity of reproducing new tissues, inclusive different embryonic layers, has permitted us to design new treatments once considered impossible.

Key Words: Human pluripotent stem cell, human embryonic stem cells, human embryonic germ cell, medical ethics, human embryo research, fetal tissue research, fetal tissue transplantation.

La posibilidad de realizar tratamientos médicos en enfermedades tan diversas y de difícil manejo en la práctica clínica como la diabetes mellitus, la esclerosis múltiple, la enfermedad de parkinson, las cardiomiopatías, las enfermedades hepáticas, las distrofias musculares y una serie de lesiones agudas como el manejo de quemaduras, lesiones de la médula espinal, accidentes vasculares cerebrales e infartos del miocardio utilizando una sola fuente de células parecería haber sido extraído del Mundo Feliz de Aldous Huxley, un cuestionado y visionario libro de ciencia ficción. Sin embargo, publicaciones recientes acerca de la obtención de células madre de origen embrionario ${ }^{1,2}$ y su posterior derivación en diferentes tejidos nos coloca dentro de una nueva realidad en este siglo XXI. Si bien lo anterior representa un gran avan- 
ce en el campo de la medicina utilizando las células madre, su origen sea embrionario o de tejido fetal ha generado una gran controversia en el campo de lo ético y lo legal. ${ }^{3-5}$

Los diferentes grupos de investigadores en este campo han encontrado resultados aceptables utilizando células madre adultas obtenidas de sangre periférica, logrando su transformación en diferentes tejidos. Sin embargo aún quedan preguntas fundamentales por responder, tales como ¿qué define una célula madre en términos moleculares? ¿Qué eventos o señales controlan la diferenciación celular y qué se necesita para reprogramar una célula? ${ }^{6}$ Es probable que la cantidad de linajes conocidos de células madre no presenten metabolismos comunes por lo que a cada grupo pluripotente le corresponderá un conjunto de reglas diferentes. ${ }^{6}$

La historia de las células madre embrionarias se inicia con el estudio de los teratocarcinomas, estos son extraños tipos de tumores gonadales que contienen varios tipos de tejidos derivados de las tres capas germinales del embrión

Tabla 1. Comparaciones entre células madre de diferente procedencia

\begin{tabular}{lcccc} 
& EC & EG & ES & MAPC \\
\hline Procedencia & PGC & PGC & ICM & ABM \\
\hline Cariotipo & Het & Eu & Eu & Eu \\
\hline Fosfatasa alcalina & + & + & + & + \\
\hline Telomerasa & + & + & + & ND \\
\hline Oct4 & + & + & + & $+/-$ \\
\hline Diferenciación in vitro & + & + & + & + \\
\hline
\end{tabular}

Diferenciación en la mayoría

\begin{tabular}{lcccc} 
de líneas celulares & + & + & + & + \\
\hline Necesita LIF & ND & ND & + & + \\
\hline Produce Línea germinal & + & + & + & ND \\
\hline Posibilidad de auto-transplante & ND & ND & - & + \\
\hline
\end{tabular}

EC: células madre embrionarias de carcinoma, provenientes de las células primordiales germinales (PGC); EG: células madre embrionarias germinales; ES: células madre embrionarias, provenientes de la masa celular interna (ICM); MAPC: células progenitoras adultas multipotenciales, provenientes de la médula ósea (ABM). Het: Heteroploide; Eu: Euploide. ND: sin datos/sin conocerse. ${ }^{7,25}$. (endodermo, mesodermo, ectodermo). Estas células fueron estudiadas inicialmente por Leroy Stevens y aunque la idea de utilizarlas apareció desde los 70, estas nunca han sido vistas como ideales debido a que proviene de tumores y presentaban aneuploidías. ${ }^{6-7}$

Existen dos tipos reconocidos de células madre, las células pluripotentes, derivadas de embriones y las células multipotentes provenientes de embriones o de adultos. La diferencia radica en la capacidad de cada una para generar la línea germinal del organismo, siendo las pluripotentes capaces de generar la línea en cuestión. ${ }^{6}$

Células madre pluripotentes, capaces de producir (teóricamente) todos los tipos celulares presentes en un organismo superior incluyendo la línea germinal, han sido aisladas de tres líneas celulares: células cancerosas embrionarias, células embrionarias pluripotentes, y células embrionarias germinales. ${ }^{7}$ Estas células pluripotentes poseen varias características en común, entre ellas, algunos marcadores moleculares como la isoenzima de la fosfatasa alcalina, un dominio del factor de transcripción Oct4, alta actividad de la telomerasa, y varios marcadores de membrana reconocidos por anticuerpos monoclonales (tabla 1). ${ }^{7}$

Recientemente se ha descrito una línea de células madre, si no pluripotentes, multipotenciales, que son capaces de proliferar indefinidamente in vitro, también son relativamente parecidas a las células madre embrionarias y posiblemente serían los equivalentes de estas en el adulto. Estas células fueron llamadas células progenitoras multipotenciales adultas (MAPC, por sus siglas en in- 
glés) por Jiang et al. ${ }^{8}$ (tabla 1). Estas células derivadas de la médula ósea pueden ser una forma rara de células pluripotentes que se mantienen desde el embrión hasta la forma adulta, sin embargo esto no está probado, además que se necesita investigar mucho acerca de sus marcadores y comportamiento in vivo. ${ }^{9}$

La función de algunos de estos marcadores sigue siendo desconocida, sin embargo se ha reconocido que el factor Oct4 tiene un papel determinante en el establecimiento y mantenimiento del estado pluripotencial, es decir indiferenciado y capaz de generar diferentes tipos celulares. ${ }^{7}$

La capacidad de las células madre para transcribir la telomerasa se correlaciona con la expectativa de vida de un linaje. La telomerasa es una ribonucleoproteína que adiciona repeticiones teloméricas a los extremos de los cromosomas. ${ }^{10}$

Las células diploides humanas no expresan la telomerasa en su fenotipo, por lo que su expectativa de vida se ve acortada. ${ }^{8}$

Los marcadores moleculares permitirían reconocer y extraer células madre in vivo, aumentando nuestro conocimiento acerca de la distribución y frecuencia de éstas en el organismo. ${ }^{9}$ La mayoría de los experimentos con células madre parte de una población de éstas, mas no de células individuales, por lo cual es posible que se estén analizando varios linajes cada uno con un potencial único, por esto el reconocimiento de marcadores moleculares únicos para cada linaje obtiene más importancia. ${ }^{6}$ Una alternativa para generar poblaciones puras de células diferenciadas podría ser el aislamiento de células especificas a partir de poblaciones mezcladas utilizando diferentes métodos como a) la morfología y propiedades biofísicas como la densidad; b) selección de epítopes por anticuerpos específicos de cada linaje; c) utilización de cultivos selectivos favoreciendo el crecimiento o adhesión de diferentes linajes; d) la selección de linajes utilizando promotores linaje-específicos que llevan a la transcripción de marcadores moleculares o genes que dan características específicas.

\section{EL MICROAMBIENTE DE}

\section{LA CÉLULA MADRE}

El uso de una capa de soporte de fibroblastos mitóticamente inactivos para el cultivo de células madre ha permitido mantener líneas celulares indiferenciadas para su investigación, sin embargo la diferenciación espontánea de estos linajes ocurre con facilidad por lo que en estas investigaciones es necesaria la creación de subcultivos de células que aún permanezcan indiferenciadas. ${ }^{12} \mathrm{~A}$ pesar de nuestra capacidad para cultivar estas células, la verdadera naturaleza de las células madre solo puede ser reconocida descubriendo los mecanismos que las regulan. ${ }^{11}$ Por esto el estudio del microambiente o nicho particular que rodea a las células madre, permitiéndoles permanecer en su estado indiferenciado y de autoperpetuación, es de gran importancia. Sin embargo estos nichos han sido solo parcialmente inferidos debido a la dificultad de manipular e identificar células madre individuales. ${ }^{13}$

Un nicho se reconoce porque aunque las células madre que contiene desaparezcan, éste se mantiene y el destino de las células madre será irrelevante para el mismo. Además el nicho específico de cada linaje definirá de manera precisa la forma de dividirse de la célula madre y el destino que las células hijas tendrán. Por ejemplo, los nichos pueden orientar la división de sus células multipotentes haciendo que sólo una de las células hija herede las moléculas de unión a la membrana basal de nicho, permitiendo que una célula se libere del nicho y proceda a diferenciarse; por el contrario si el nicho permite que las dos células hijas hereden las moléculas de contacto entonces la población de células madre se mantendrá estable. ${ }^{13}$ Estos tipos de divisiones en un nicho son divisiones asimétricas, que han sido denominadas asimetría invariable y asimetría poblacional respectivamente. ${ }^{14}$ Durante una división celular asimétrica cada una de las células hijas puede adquirir un potencial diferente de desarrollo, ${ }^{13}$ posiblemente el nicho de las células madre en la 
mayoría de los tejidos de los mamíferos presente un tipo de división asimétrica poblacional, esta división, a diferencia de la división invariable permite la generación de un continuo de células madre y progenitoras permitiendo que la asimetría se alcance a partir de la población y no de divisiones celulares individuales. ${ }^{14}$

El nicho también ejerce control sobre la célula madre mediante factores secretados. La secreción de factores de crecimiento y mantenimiento fue descrita inicialmente en la hematopoyesis, en éste sistema la función de los factores secretados parece ser selectiva, ${ }^{14}$ mientras que en las células madre de la cresta neural los factores pueden jugar un papel instructivo en la diferenciación. ${ }^{13,14}$ Dos familias de factores presentan una función conservada entre especies y tejidos. El factor transformante de crecimiento b-relacionado (TGF-b) y el factor Wnts. Estos factores activadores de la transcripción participan en la diferenciación de células madre de diferentes nichos. ${ }^{14}$ En el nicho germinal las células de Sertoli producen el factor TGF-b el cual afecta la proliferación de células germinales pre-meióticas, incluyendo a las células madre. ${ }^{13}$ En el nicho epidermal los factores TGF-b RII y Wnt parecen inducir la generación de folículos pilosos, además el factor Wnt también permite la diferenciación de las células a células foliculares y no keratinocitos, ${ }^{13}$ por lo menos dos miembros de la familia TGF-b son importantes en la regulación de la diferenciación de las células madre de la cresta neural. ${ }^{14}$

La adhesión de las células madre a la membrana basal del nicho es mediada por moléculas de adhesión, siendo las integrinas las más ampliamente caracterizadas. Las integrinas mantienen a las células madre en posición y la pérdida o alteración de estas moléculas causa que las células madre se diferencien o inicien la apoptosis, además las integrinas pueden activar receptores de factores de crecimiento. ${ }^{14}$ Las integrinas a y b se encuentran sobre-expresadas en la capa basal del nicho ger- minal de los mamíferos, lo cual permite que las células madre de las espermatogonias se mantengan unidas al nicho. ${ }^{13}$

El nicho del epiblasto pluripotente, en el embrión humano, es proporcionado por los tejidos extraembrionarios, como el trofoblasto y el endodermo visceral. La región anterior del endodermo visceral secreta una señal relacionada a el factor TGF-b el cual controla la diferenciación de la parte más anterior de los linajes embrionarios. Las células de la línea germinal y mesodérmica son inducidas por el factor Bmp4 producido por las células del trofoblasto. ${ }^{14}$

\section{FACTORES DE TRANSCRIPCIÓN Y AUTO-RENOVACIÓN}

Las células madre producen factores de transcripción que interactúan con los factores producidos por las células del nicho, es probable que los factores de transcripción controlen el destino de la célula madre así como su auto-renovación, además cada linaje se encuentra controlado por una combinación única de estos factores, inclusive estos factores pueden ser expresados individualmente en diferentes linajes. ${ }^{14}$ En la hematopoyesis del ratón los factores SCL/Tal-1 son esenciales en la formación de todos los tipos de linajes celulares. En el epitelio intestinal y epidermal la familia de factores Tcf/Lef juegan un papel muy importante, los cuales son activados por la b-catenina. El factor Tcf-4 es mediador de señales que permiten la formación y el mantenimiento de las criptas intestinales (nicho intestinal). Mutaciones en la bcatenina producen complejos Tcf-4/b-catenina constitutivamente lo cual acelera la proliferación de las células madre. ${ }^{13}$

En general los nichos pueden modificar sus propiedades reguladoras a las células madre en respuesta a las condiciones presentes, asegurando que las células madre se encuentren en sincronía con las necesidades particulares del organismo. ${ }^{13,14}$ Este control permite que las células madre se di- 
vidan en sincronía y la población se mantenga estable, en condiciones normales para el organismo; sin embargo, es probable que las células madre de un nicho no se encuentren en la misma fase del ciclo celular en el momento en que el organismo necesita la producción de progenitores. A pesar de esto en el microambiente hematopoyético las células madre entran en división al menos cada 6 meses y el 90\% de ellas lo hace cada 30 días. $^{15}$

A pesar de las diferencias estructurales y funcionales de los diferentes nichos, estos pueden funcionar bajo reglas comunes. Varios de los microambientes descritos usan uno o más grupos especializados de células de soporte. Una señal principal originada dentro de las células especializadas es recibida por la célula madre y controla su comportamiento aunque la cascada de señales subsiguientes sea muy compleja en cada nicho. Una membrana basal hace parte de la mayoría de los microambientes estudiados, una matriz extracelular que ayuda a estructurar los nichos espacialmente y modula la concentración de moléculas de señalización y de adhesión. ${ }^{13,14}$

Uno de los más importantes tópicos en el entendimiento de las células madre es la auto-renovación. La auto-renovación es requerida por todos los tipos de células madre para persistir en el tiempo. El mecanismo de auto-renovación es fundamental para reconocer los mecanismos de regulación de las células cancerosas. ${ }^{16}$

Los factores Notch, Shh (Sonic hedgehog) y Wnt pueden regular los mecanismos de auto-renovación. En las células madre hematopoyéticas, la activación de Notch promueve la auto-renovación o al menos el mantenimiento de la multipotencialidad. La señalización por medio del factor Shh también se encuentra implicada en la regulación de la autorenovación de células madre hematopoyéticas, neurales y de la línea germinal. El factor Notch también se encuentra implicado en la señalización de estos tipos de células madre. ${ }^{16}$
El factor Wnt que también forma parte de los factores secretados, promueve la auto-renovación en una variedad de tejidos entre los cuales esta la hematopoyesis, la generación de la epidermis y del epitelio intestinal. ${ }^{16}$

En el embrión de roedor las células madre embrionarias pueden mantener su condición pluripotente cuando el factor inhibidor de leucemia (LIF) se encuentra presente y este a su vez hace que se exprese otro factor, el Oct4, uno de los marcadores del estado pluripotencial. Cuando el factor LIF es retirado del medio, las células rápidamente regulan el factor Oct4 perdiendo la capacidad de auto-renovación y diferenciándose en una variedad de tipos celulares. ${ }^{17}$

La vía por la cual el factor LIF promueve la auto-renovación de las células madre embrionarias de roedor ocurre por la heterodimerización de dos clases de receptores de citoquinas tipo I, el receptor de baja afinidad a LIF (LIF-R) y la unidad común gp $130 .{ }^{17}$ Sin embargo el papel que juega LIF in vivo, en el desarrollo del embrión aún no es completamente claro. Aunque como se esperaría para el mantenimiento de las células pluripotenciales in vivo, el LIF se expresa en el trofoectodermo y su receptor en la masa interna celular (ICM). ${ }^{17}$

\section{PLASTICIDAD}

El potencial de las células madre para generar tejidos de diferentes capas embrionarias podría facilitar el acceso a estas células con fines experimentales y terapéuticos. Así, las células madre del tejido de la epidermis que se encuentran distribuidas a lo largo del órgano más extenso del cuerpo humano, facilitarían su selección y cultivo posterior. Además, el uso de células madre somáticas para transplantes autólogos de cualquier tejido permitiría eliminar el uso de células madre embrionarias pluripotenciales, disminuyendo los problemas éticos y técnicos relacionados con el uso de las células de embriones humanos. ${ }^{18}$ 
Sin importar que tan diferente sea, por ejemplo, un hepatocito de una neurona, la mayoría de las células mantiene su genoma intacto con un complemento de genes que se encuentra presente desde la formación del zigoto. ${ }^{19}$ Debido a esto las características específicas de una célula aparecen por una selección de genes que son expresados mientras el resto de genes es silenciado. ${ }^{19}$

Sin embargo la plasticidad de las células madre, definida como la capacidad de estas células para cruzar los límites entre los linajes celulares, ${ }^{6}$ ha sido ampliamente discutida ya que esta capacidad podría violar las reglas de la embriología en donde una célula proveniente de una de las capas embrionarias (ectodermo, mesodermo, endodermo) no podría generar células características de otra de estas capas. A pesar de esto la trasgresión de esta regla ha sido reportada ya varias veces. ${ }^{6,20}$ Tal es el caso de las células madre neurales adultas que cultivadas in vitro en un microambiente con factor epidérmico de crecimiento y factor de crecimiento de fibroblastos, e inyectadas después en un huésped irradiado se recuperaron luego células madre en el compartimiento hematopoyético que procedían de las células madre neurales. ${ }^{21}$ Esto podría sugerir que las células madre que se originan de diferentes tejidos compartirían un programa genético común que las mantendría en su estado indiferenciado y auto-renovador ${ }^{22}$ y la diferenciación ocurriría a partir de múltiples tipos de factores presentes en cada uno de los diferentes microambientes en los que las células madre se encuentran, por lo que el microambiente o nicho en el que se presenta una célula madre es crucial para su diferenciación en diferentes tipos de tejidos. ${ }^{18}$ Se ha sugerido entonces que las células madre pueden existir en todos los tejidos y que estas poblaciones de células madre tienen la capacidad de generar cualquier tejido dependiendo del tipo de nicho en que se encuentren. ${ }^{23}$

La plasticidad de las células madre puede ser estudiada en el embrión de los roedores en su etapa de blastocisto y es probable que los resultados obtenidos así puedan ser extrapolados al humano. En los roedores en etapa de blastocisto se encuentran dos tipos de células madre: las células madre embrionarias procedentes de la masa celular interna y las células madre del trofoectodermo. Las células madre embrionarias generan todos los tejidos del feto, mientras que las células madre del trofoectodermo se restringen a la generación de la capa de células trofoblásticas de la placenta. Estos dos tipos celulares dependen de dos nichos totalmente diferentes, sin embargo las células madre embrionarias pueden cambiar hacia el destino trofoblástico por medio de la alteración de las condiciones de cultivo, incluyendo la alteración de los niveles en la expresión del factor Oct4, un determinante clave de la pluripotencialidad. ${ }^{17}$

Estos resultados aunque asombrosos, no deben dejar de ser analizados rigurosamente ya que varios de los experimentos donde se ha observado trasgresión de células madre de una capa embrionaria a otra han sido realizados con combinaciones de poblaciones celulares y no con poblaciones puras. Posiblemente la heterogeneidad de células presentes pueda ser la respuesta a los resultados observados ${ }^{23,24}$ por esto el conocimiento de marcadores específicos de superficie que permitan reconocer y diferenciar poblaciones puras de células madre es de suma importancia. ${ }^{22}$ Aunque existen reportes de reprogramación de genomas de células madre a partir de poblaciones puras, estos resultados pueden deberse a eventos de transformación raros o a fusión de las células donadas con las células hospederas. Por esto, en investigaciones futuras la posibilidad de estos eventos debe ser de alguna forma excluida. ${ }^{24}$

Aunque en teoría las células madre adultas podrían diferenciarse en tejidos diferentes al de su origen, como la obtención de células hematopoyéticas a partir de células neurales adultas, ${ }^{21}$ esto realmente no se relacionaría con la plasticidad si no con un evento de fusión celular, ${ }^{25}$ en el cual las 
células madre adultas al ser cultivadas con las células madre embrionarias se fusionarían, debido a esto las células madre adultas cuando son analizadas expresan entonces la pluripotencialidad conferida por las células madre embrionarias a la vez que los marcadores moleculares las identifican como las células madre adultas. ${ }^{25}$ Cuando los investigadores analizaron estas células fusionadas, se observó que estas células expresaban dos tipos de marcadores moleculares, cada uno perteneciente a un tipo de célula madre, inclusive algunas de estas células fusionadas contenían el doble del material genético. ${ }^{26}$ Por medio de la fusión espontánea las células expresaban marcadores moleculares típicos de cada línea. Según Terada et al. ${ }^{26}$ al cultivar poblaciones de células madre de la médula ósea y células madre embrionarias, las células de la médula adoptan el fenotipo de las otras células En un experimento similar Ying et al. ${ }^{26}$ cultivaron al tiempo células madre neurales de ratón y células madre embrionarias. Los resultados sugirieron también que la fusión celular había tomado lugar. ${ }^{26}$

Es probable que debido a las condiciones altamente selectivas en que las células fueron cultivadas, se estimulara una fusión "artificial" como único medio que tenían estas células para poder sobrevivir. Sin embargo a partir de estos resultados es indispensable que los datos in vivo que hablan sobre la diferenciación de células madre en tejidos de diferentes capas embrionarias sean revisados. ${ }^{25}$

A pesar de la fusión celular, Jiang et al., ${ }^{8}$ propone la existencia de células madre (MAPC) capaces de diferenciarse en las tres capas embrionarias al ser cultivadas in vitro, ya que al ser transplantadas in vivo a un roedor se diferenciaron en células del endotelio, y del sistema hematopoyético (figura 1). Más aún estos resultados no pudieron ser relacionados con la fusión celular, por lo que estas células madre podrían ser una nueva fuente de células madre adultas. ${ }^{9}$

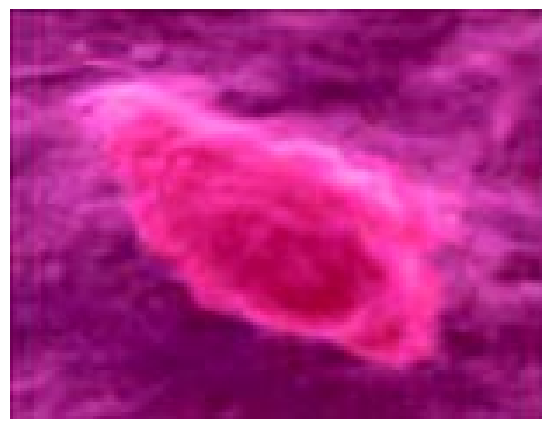

Figura 1. Fotografía de una célula madre hematopoyética.

\section{ASPECTOS CLÍNICOS}

Debido a que las células madre tienen el potencial de diferenciarse en cualquier tipo de célula en el organismo, existe la esperanza que ellas lleven al diseño de tratamientos para enfermedades como el mal de Parkinson, Alzheimer, insuficiencia cardiaca, esclerosis múltiple, enfermedad de Huntington, lesiones de la médula espinal, ${ }^{27}$ así como el diseño de tejidos nuevos, tales como la piel. ${ }^{28}$ Además el entendimiento de los diferentes y múltiples factores que regulan la autoreplicación de estas células podría llevar al entendimiento de muchas formas de cáncer.

La aplicación clínica de las células y el transplante de sus progenitores comenzó cuando la humanidad se expuso a radiaciones letales producidas por el advenimiento de la era nuclear en 1945. En esa época se experimentó en ratones el efecto de esa radiación, demostrándose que el transplante de médula ósea proveía a los ratones de una nueva fuente de tejido hematopoyético, el cual se presentaba disminuido debido a las radiaciones. ${ }^{29}$ En 1961 Till y McCulloch demostraron la existencia de precursores hematopoyeticos y propusieron que estas células tenían la habilidad de auto-renovarse y de generar varias líneas de tejidos. Aunque estos experimentos develaron la existencia de las células madre, no fue posible obtener su aislamiento. ${ }^{29}$

El problema con el potencial de estas células es controlar su crecimiento y diferenciación. Si 


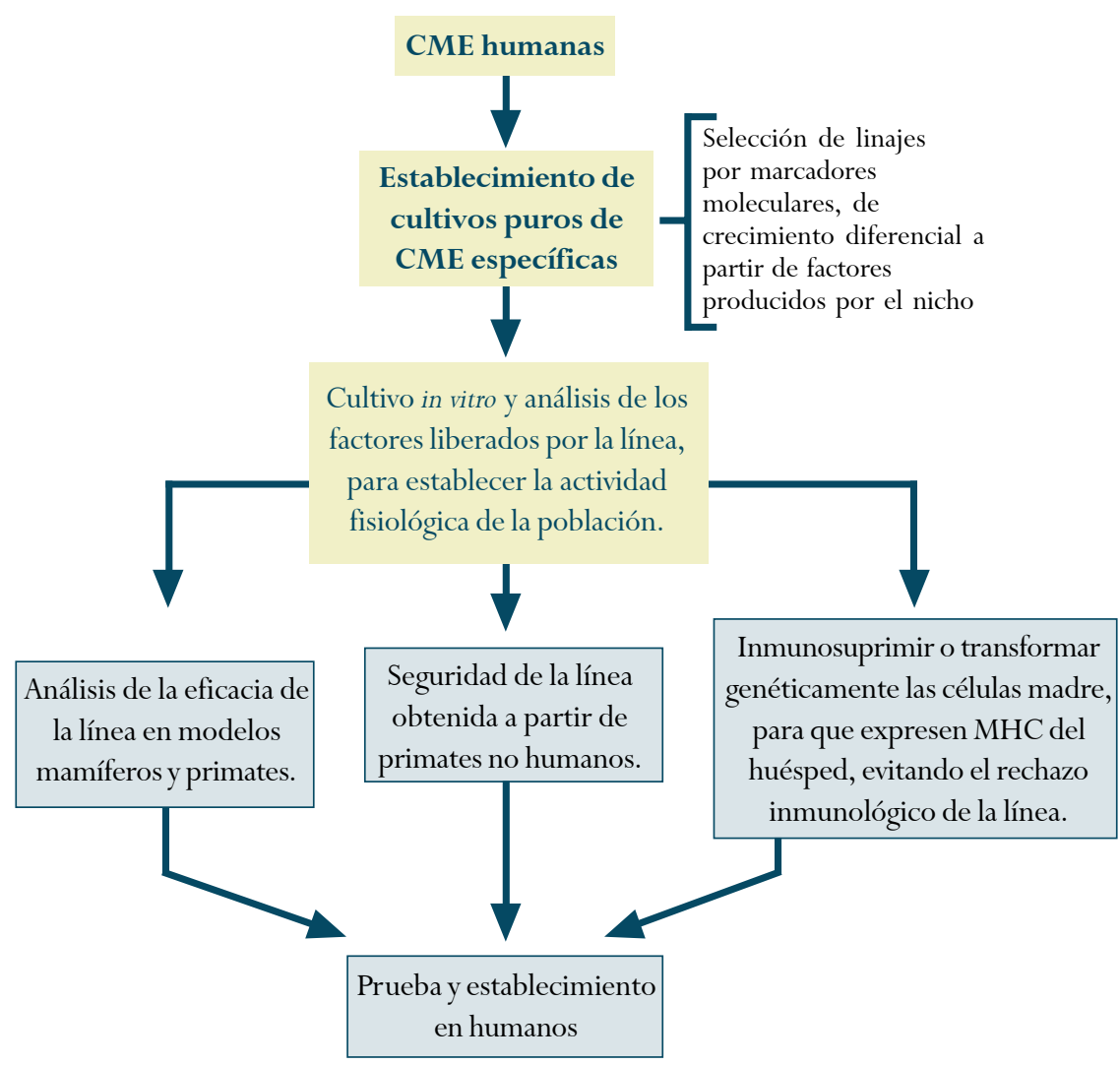

Figura 2. Representación gráfica de los posibles pasos que deberían seguirse para usar las células madre embrionarias en terapias clínicas. CME: célula madre embrionaria; MHC: complejo mayor de histocompatibilidad. estudios recientes han mostrado que estas células son capaces de expresar MHC (complejo mayor de histocompatibilidad) en humanos, aunque en niveles más bajos a la norma producida por una célula diferenciada. A pesar de esto el potencial de expresar el MHC podría ser evitado diseñado genéticamente a estas células (figura 2). ${ }^{30}$ El rechazo también podría ser evitado usando transplantes autólogos, provenientes de células madre del organismo. ${ }^{30}$ Las células madre MAPC (células progenitoras multipotentes adultas) podrían ser una fuente de células madre para transplantes autólogos (tabla 1). Estas células pueden diferenciarse en células hematopoyéticas y de varios tejidos in vivo y pueden ser seleccionadas de la médula ósea prograndes números de células madre embrionarias son transplantadas a un órgano, como el cerebro, estas crecen diferenciándose en todos los tipos celulares, formando un teratoma. ${ }^{27}$

Las enfermedades tratadas con células madre embrionarias pertenecerían a dos categorías: la primera sería el tratamiento de enfermedades que requieren el reemplazo específico de líneas celulares, como las neuronas productoras de dopamina en la enfermedad de Parkinson, y la segunda categoría sería el tratamiento de reemplazo de las células madre que han fallado, como el transplante de células madre en una anemia aplásica. ${ }^{27}$

El uso de células madre embrionarias en transplantes no autólogos puede llevar a que estas células sean rechazadas por el organismo. Anteriormente la evidencia mostraba que estas células no eran reconocidas por el sistema inmune del huésped, pero pia del paciente a ser tratado. Usando este tipo de células no sería necesario transformar células madre embrionarias para evitar la producción de MHC y el subsiguiente rechazo. ${ }^{25}$

\section{POTENCIALES USOS DE LAS CÉLULAS MADRE}

- El requerimiento de las células madre en la enfermedad de Parkinson es generar células que sean capaces de sintetizar y liberar dopamina después de ser implantadas en la zona estriada, sin embargo no se ha reconocido si las células deben madurar en neuronas con proyecciones sinápticas con las neuronas huésped. ${ }^{11}$ Las células derivadas de la región media cerebral del feto pueden modificar el curso de esta enfermedad, aunque debe tenerse en cuenta ellas son una fuente inadecuada de neuronas producto- 
ras de dopamina debido a su inestabilidad; así, el uso de células madre embrionarias es una mejor opción debido a la mayor estabilidad de las neuronas generadas. ${ }^{31}$

- En la enfermedad de Huntington se debe lograr controlar la maduración de células madre en neuronas maduras que sean capaces de generar las proyecciones neurales perdidas en esta enfermedad. ${ }^{11}$

- En el daño de médula espinal las células madre podrían restablecerse en el sitio de la lesión y proveer un substrato para el crecimiento del axón a través del daño medular. ${ }^{11}$

- Las células madre pueden ser usadas en el diseño y reparación de tejidos, como el esqueleto y la epidermis. El diseño de la forma y la estructura física de un implante como la epidermis es relativamente fácil y puede ser lograda en condiciones ex vivo mientras que los sistemas como el esqueleto no pueden ser generados ex vivo debido a la difícil reconstrucción de su forma tridimensional. Estudios piloto en una variedad de sistemas han demostrado un gran potencial usando estas células en la ingeniería de tejidos. Para que las células madre adultas puedan ser usadas eficazmente en la regeneración de tejidos, los factores que influyen en su diferenciación y mantenimiento deben ser completamente entendidos. ${ }^{32}$

- La esclerosis múltiple puede ser tratada usando los precursores de los oligodendrocitos que podrían diferenciarse y ser una fuente de remielinización. Sin embargo el principal problema con esta enfermedad es cómo estimular la migración de esas células a los diversos sitios sin mielina. ${ }^{11}$

\section{CONCLUSIÓN}

La implementación y mejoría de las técnicas de cultivos de las células madre humana nos ofrece la posibilidad de acercarnos al conocimiento de los eventos que controlan la biología y la medicina humana. El haber podido mejorar esta tecnología nos brinda la posibilidad de estudiar sus aplicaciones en embriología humana, genómica funcional, los factores de crecimiento implicados en su funcionamiento, descubrimiento de nuevos medicamentos, la toxicología, el transplante celular y la terapia génica. En un futuro cercano servirán de ayuda para mejorar calidad de vida y salvar vidas humanas.

El reciente descubrimiento de la posibilidad de que las células madres embrionarias se diferencien hacia líneas celulares específicas mediante factores de crecimiento es el paso inicial hacia la diferenciación controlada.

Dado el gran interés que la comunidad científica tiene en las células madre y los progresos en las investigaciones básicas y clínicas, en breve tendremos grandes avances en la aplicación de nuevas tecnologías y su aplicación clínica con los potenciales beneficios a la medicina y a la investigación.

Agradecimientos Los autores agradecen al Profesor Edgar Cobo por sus comentarios y correcciones al presente artículo.

\section{BIBLIOGRAFÍA}

1. Thomson JA, Itskovitz-Eldor J, Shapiro SS, et al. Embryonic stem cells lines derived from human blastocysts. Science 1998; 282, 1145- 1147.

2. Shamblott MJ, Axelman J, Wang S, et al. Derivation of pluripotent stem cells from cultured human primordial germ cells. Proc Natl Acad Sci USA 1998; 95: 13726-13731.

3. Weissman IL. Stem cells - Scientific, medical and political issues. N Engl J Med. 2002; 346 (20) 15761579 .

4. Evers K. European perspectives on therapeutic cloning. N Engl J Med 2002; 346(20): 1579-1582.

5. Annas GJ. Cloning and the U.S. Congress. $N$ Engl $J$ Med 2002; 346(20) 1599-1602.

6. Lovell-Badge R. The future for stem cell research. Nature 2001; 414: 88-91. 
7. Donovan P, Gearhart J. The end of the beginning for pluripotent stem cells. Nature 2001; 414:92-97.

8. Jiang Yuehua et al. Pluripotency of mesenchymal stem cells derived from adult marrow. Nature 2002; 418: $41-49$.

9. Orkin SH, Morrison SJ. Stem cell competition. Nature 2002; 418: 25- 27.

10. Thomson JA, Itskovitz-Eldor J, Waknitz M.A. et al. Embryonic stem cells lines derived from human blastocysts. Science 1998; 282: 1145- 1147.

11. Temple S. The development of neural stem cells. Nature 2001; 414: 112-117.

12. Reubinoff B. The clinical potential of human embryonic stem cells. En reproductive medicine in the twenty-first century. Eds. D.L. Healy, G. Kovacs, R. McLachlan , O. Rodriguez Armas. The Parthenon publishing group. 2001. pp 454-461.

13. Spradling A, Drummond BD, Kai T. Stem cells find their niche. Nature 2001; 414: 98-104.

14. Watt F, Hogan BL. Out of eden: stem cells and their niches. Science 2000; 287: 1427- 1430.

15. Cheshier SH, Morrison SJ, Xiensheng L, Weissman I. In vivo proliferation and cell cycle kinetics of longterm self-renewing hematopoietic stem cells. Proc. Natl. Acad Sci USA 1999; 96: 3120- 3125.

16. Reya T, Morrison S, Clarke M, Weissman I. Stem cells, cancer and cancer stem cells. Nature 2001; 414: 105-111.

17. Wurmser AE, Gage FH. Cell fusion causes confusion. Nature 2002; 416: 485-487.

18. Wei G, Schubiger G, Harder F, Müller A. Stem cell plasticity in mammals and transdetermination in Drosophila: Common themes? Stem Cell 2000; 18: 409-414.

19.Surani MA. Reprogramming of genome function through epigenetic inheritance. Nature 2001. 414, 122- 127.
20.Jackson KA, Mi T, Goodell MA. Hematopoietic potential of stem cells isolated from murine skeletal muscle. Proc Natl Acad Sci USA 1999; 96: 1448214486.

21.Bjornson $\mathrm{Cr}$ et al. Turning brain into blood: a hematopoietic fate adopted by adult neural stem cells in vivo. Science 1999; 283: 534- 537.

22. Chu VT, Gage FH. Chipping away at stem cells. Proc Natl Acad Sci USA 2001; 98: 7652- 7653.

23. Liang L, Bickenbach JR. Somatic epidermal stem cells can produce multiple cell lineages during development. Stem Cell 2002; 20: 21 - 31.

24. Hawley RG, Sobieski DA. Somatic stem cell plasticity: To be or not to be... Stem Cell 2002; 20: 195- 197.

25. Terada $\mathrm{N}$ et al. Bone marrow cells adopt the phenotype of other cells by spontaneous cell fusion. Nature 2002; 416: 542- 545.

26. Ying QL et al. Changing potency by spontaneous fusion. Nature 2002; 416: 545- 548.

27. Freed CR. Will embryonic stem cells be a useful source of dopamine neurons for transplant into patients with Parkinson's disease?. Proc Natl Acad Sci USA 2002; 99: 1755- 1757.

28. Bianco P, Robey P. Stem cells in tissue engineering. Nature 2001; 414: 118- 121.

29. Weissman IL. Translating stem and progenitor cell biology to the clinic: barriers and opportunities. Science 2000; 287: 1442- 1446.

30. Vogel G. Stem cells not so stealthy after all. Commentary. Science 2002; 297: 175-176.

31. Kim JH et al. Dopamine neurons derived from embryonic stem cells function in an animal model of Parkinson's disease. Nature 2002; 418: 50- 56.

32. Bianco P, Robey G. Stem cells in tissue engineering. Nature 2001; 414: 118- 121. 